Osgood, C.E., Suci, G.J. \& Tannenbaum, P.H. (1957) The Measurement of Meaning. University of Illinois Press. Urbana, 111.

Ross, T.A. (1938). Comment on 'pre-psychotic anorexia' (paper by G. Nicolle). Lancet, ii, 1173.
Steele, R. \& Pollock, C. (1968) Psychiatric aspects. In: The Battered Child (Ed. by R. E. Helfer and C. H. Kempe). Chicago University Press.

WeChSLER, D. (1955) Manual for the Wechsler Adult Intelligence Scale. The Psychological Corporation, New York.

Postgraduate Medical Journal (June 1972) 48, 384-385.

\title{
Toxoplasma encephalitis in a raw steak eater
}

\author{
P. J. Hollins* \\ M.B., B.Sc., M.R.C.P. \\ B. I. HoFFBRAND $\dagger$ \\ D.M., M.R.C.P. \\ I. M. HAFFAJEE \\ B.A., M.B., B.Chir.
}

Whittington Hospital, London, N.19

\section{Summary}

A case of adult acquired toxoplasma encephalitis is described. The patient was in the habit of eating raw or very lightly cooked steak, and could have obtained her infection from this source.

\section{Introduction}

The vast majority of acquired infections with the protozoan parasite, Toxoplasma gondii, are symptomless and are recognized by finding serum antibodies (Beverley, 1969). The commonest clinical manifestation of acquired toxoplasmosis is a glandular-fever-like syndrome with a negative Paul Bunnell reaction (Siim, 1956). Other modes of presentation described include uveitis (Duke-Elder, Ashton \& Brihaye-van Geertruyden, 1953), atypical pneumonia (Ludlam \& Beattie, 1963), myositis (Chandar, Mair \& Mair, 1968), myocarditis (Mullan, Henry \& Beverley, 1968), and hepatitis (Vischer, Bernheim \& Engelbrecht, 1967). Meningo-encephalitis, the most important feature of congenital toxoplasmosis (Nutt \& Beverley, 1963) also occurs with the acquired disease; Sabin (1941), Sexton, Eyles \& Dillman (1953) and Kayhoe et al. (1957) have reported severe cases which reached necropsy. However, since Sabin's original paper 30 years ago there have been few cases of toxoplasma encephalitis diagnosed during life (Beverley, 1969; Fleck, 1971). The following case is of particular interest in that the patient was fond of eating practically raw steak. This fact may be relevant to the as yet uncertain mode of transmission of the organism in man.

\section{Case report}

A 23-year-old married theatre sister was admitted to hospital in October 1970 as an emergency having become confused on her way to work. She had been

* Present address: Clinical Research Centre, Watford Road, Harrow, Middlesex, HA1 3 UJ.

$\dagger$ Requests for reprints: Dr B. I. Hoffbrand, Whittington Hospital, London, N.19. well until 8 days previously when she developed diarrhoea and vomiting which lasted 4 days. Fortyeight hours prior to admission she became drowsy, developed headache, photophobia and pain about the eyes and vomited. A history was obtained later that she ate extremely undercooked and, on occasions, even raw steak. She kept a budgerigar at home. There was no other history of contact with animals.

On examination: Temperature $99^{\circ} \mathrm{F}$. Drowsy, irritable with photophobia and mild neck stiffness. Fundi normal. No neurological signs, lymphadenopathy or splenomegaly. General examination normal.

Investigations: $\mathrm{Hb}, 16.2 \mathrm{~g} / 100 \mathrm{ml}$; WCC, $7700 /$ $\mathrm{mm}^{3}$; lymphocytes, $52 \%$; ESR $6 \mathrm{~mm} / \mathrm{hr}$. Cultures and microscopy of blood, urine, stool-normal. No viruses isolated from stool. CSF: normal pressure. WCC, $1 / \mathrm{mm}^{3}$; protein, $38 \mathrm{mg} / 100 \mathrm{ml}$; sugar, 50 $\mathrm{mg} / 100 \mathrm{ml}$; WR and Lange, negative. No viruses grown. Glandular fever screening tests, negative. Extending Widal compatible with previous $\mathrm{TAB}-$ no rise in titre. Immunoglobulin levels-normal. Mantoux 1 in 10,000 -positive. Serum glutamic oxaloacetic transaminase $76 \mathrm{Karmen}$ units $/ \mathrm{min} / \mathrm{ml}$. ECG -widespread $\mathrm{T}$ wave flattening. Serum bilirubin, alkaline phosphatase, chest X-ray, Reiter CFT and Kahn-all normal. Toxoplasma dye test titre-zero.

Progress. The patient's symptoms and low-grade irregular fever subsided spontaneously over 3 weeks and she was discharged to convalesce at home. Ten days later she was re-admitted with further headache, photophobia and fever, and a complaint of dropping things from her right hand. The physical signs were unchanged as were her blood count and CSF. The ECG and SGOT were now normal. An EEG was also normal. The toxoplasma dye test titre had now become positive at 1 in 2000 . No toxoplasma were isolated from stool or CSF. A second serum showed no rise in titre or evidence of co-incidental infection with mumps, herpes simplex. lymphocytic choriomeningitis viruses, or leptospirosis. 
Treatment with Sulphatriad $3 \mathrm{~g}$ and pyrimethamine $25 \mathrm{mg}$ daily relieved her symptoms and fever after $48 \mathrm{hr}$. The drugs were discontinued when thrombocytopenia developed 10 days later. Folinic acid was then given intramuscularly with a good haematological response. The toxoplasma dye test titre rose to 1 in 64,000 and the patient's symptoms recurred a third time, 4 months after her initial admission. A month's course of sulphadiazine $6 \mathrm{~g}$, pyrimethamine $25 \mathrm{mg}$ and folinic acid $9 \mathrm{mg}$ i.m. daily was given uneventfully and 6 months later she remains well. At no time was there any lymphadenopathy clinically.

\section{Comment}

The diagnosis of acute toxoplasmosis seems well established here with the appearance of high antibody titres in the toxoplasma dye test during the course of a remitting encephalitic illness. A subclinical myocarditis was also documented upon serial ECGs in the earlier stages of the disease.

Toxoplasma gondii is widely dispersed in man and many species of animals and birds but the mode of transmission is uncertain. It has been suggested that ingestion of infected meat could be a source of infection in man. The organism is readily killed by only moderate degrees of heat as may be found in grossly undercooked joints of meat (Garnham \& Lainson, 1960). However, Desmonts (1962) has shown that introducing uncooked meat into the diet of institutionalized children was followed by the production of toxoplasma antibodies. The dietary habits of the present patient may therefore be relevant to her illness. The diarrhoea and vomiting which preceded the encephalitic illness by about 1 week, could conceivably have been due to massive gastro-intestinal infestation following ingestion of infected raw steak. Toxoplasma was not isolated from the patient's budgerigar's stools and the patient's husband's toxoplasma dye test titre was zero 2 months after the onset of her illness. The latter is a further pointer against a common airborne or dietary source. Her husband is not a raw steak eater. Pyrimethamine is an antifolate agent and may produce haematological complications. Folinic acid prevents or reverses these and does not interfere with the toxoplasmacidal effect (Beverley, 1969). It should therefore be given routinely with sulphonamide and pyrimethamine in the treatment of toxoplasmosis.

\section{Acknowledgment}

Our thanks are due to Dr D. G. Fleck, Public Health Laboratory, St George's Hospital, Tooting, S.W.17, for the toxoplasma antibody and isolation studies and for much helpful advice.

\section{References}

Beverley, J.K.A. (1969). Toxoplasmosis in man. British Journal of Hospital Medicine, 2, 645.

Chandar, K., Mair, H.J. \& MaIR, N.S. (1968) Case of toxoplasma polymyositis. British Medical Journal, 1, 158.

Desmonts, G. (1962) Epidémiologie de la toxoplasmose. Revue d'Hygiène et de Médicine Sociale, 10, 201.

Duke-Elder, S., Ashton, N. \& Brihaye-van Geertruyden, M. (1953) Toxoplasmosis in the adult. British Journal of Ophthalmology, 37, 321.

FLECK, D.G. (1971) Personal communication.

Garham, P.C.C. \& Lainson, R. (1960) Sheep as a potential reservoir of toxoplasma in man. Lancet, ii, 71.

KAYHOE, D.E., JACOBS, L., BeYe, H.K. \& McCullough, N.B. (1957) Acquired toxoplasmosis. Observations on two parasitologically proved cases treated with pyrimethamine and triple sulphonamides. New England Journal of Medicine, 257, 1247.

Ludlam, G.B. \& Beattie, C.P. (1963) Pulmonary toxoplasmosis. Lancet, ii, 1136.

Mullan, D.P., HenRy, L. \& Beverley, J.K.A. (1968) Toxoplasmosis and myocarditis. British Medical Journal, 4, 559.

NuTT, A.B. \& BeVERLEY, J.K.A. (1963) Ocular toxoplasmosis. Transactions of the Ophthalmological Society of Australia, 23, 35 .

SABIN, A.B. (1941) Toxoplasmic encephalitis in children. Journal of the American Medical Association, 116, 801.

Sexton, R.C., Eyles, D.E. \& Dellman, R.E. (1953) Adult toxoplasmosis. American Journal of Medicine, 14, 366.

SiIM. J.C. (1956) Toxoplasmosis acquisita lymphonodosa: clinical and pathological aspects. Annals of the New York Academy of Sciences, 64, 185.

Vischer, T.L., Berhneim, C. \& Engelbrecht, E. (1967) Two cases of hepatitis due to toxoplasma gondii. Lancet, ii, 919. 